\title{
Treatment preferences among Japanese women with dysmenorrhea: results from a discrete choice experiment study
}

This article was published in the following Dove Press journal:

Patient Preference and Adherence

\section{Sayako Akiyama' \\ Amir Goren ${ }^{2}$ \\ Enrique Basurto ${ }^{2}$ \\ Tetsushi Komori ${ }^{3}$ \\ Tasuku Harada ${ }^{4}$}

'Market Access, Bayer Yakuhin, Ltd., Tokyo, Japan; ${ }^{2}$ Health Outcomes Practice, Kantar Health, New York, NY, USA; ${ }^{3}$ Clinical Statistics, Bayer Yakuhin, Ltd., Osaka, Japan; ${ }^{4}$ Department of Obstetrics and Gynecology, Tottori University, Tottori, Japan
Correspondence: Sayako Akiyama Market Access, Bayer Yakuhin, Ltd., 6-5, Marunouchi I-chome, Chiyoda-ku,

Tokyo 100-8265, Japan

Tel +8I 362667759

Fax +81332826713

Email sayako.akiyama@bayer.com
Purpose: To examine patient preferences for oral and intrauterine system treatments for dysmenorrhea in Japan.

Patients and methods: A discrete choice experiment was conducted to assess the willingness to accept trade-offs among hypothetical treatment profiles. An internet-based survey was administered to women 18-49 years of age who self-reported a dysmenorrhea diagnosis or experienced dysmenorrhea at least once in the past 6 months $(\mathrm{N}=309)$. Choice questions included pairs of treatments presented with different attributes: mode of administration, reduction in bleeding after 6 months, chance of symptoms becoming "improved", nausea, weight gain, irregular bleeding, and risk of venous thromboembolism. Relative importance (RI) estimates were computed.

Results: The mean respondent age was 35.8 years (standard deviation $=7.0$ ), and 85 women $(27.5 \%)$ reported that they had previously used hormonal therapy for dysmenorrhea. Treatment preference was most strongly associated with mode of administration $(\mathrm{RI}=49.8 \%)$, followed by chance of irregular bleeding $(\mathrm{RI}=17.3 \%)$. In contrast, treatment preference was most weakly associated with chance of weight gain $(\mathrm{RI}=2.4 \%)$ and reduction in bleeding after 6 months $(\mathrm{RI}=0.8 \%)$. Respondents preferred oral treatments: for twice-daily regimen, odds ratio $(\mathrm{OR})=4.90$; for once-daily fixed cyclic regimen, $\mathrm{OR}=4.20$; and for once-daily flexible extended regimen, $\mathrm{OR}=2.44$; whereas for intrauterine system, $\mathrm{OR}=0.02(p<0.001$ for all). Those with prior hormonal therapy experience exhibited the same pattern.

Conclusion: Mode of administration factored heavily in dysmenorrhea treatment preferences. Women of reproductive age preferred oral medication, especially twice-daily regimen and once-daily fixed cyclic regimen. Findings can potentially help to improve physician-patient communication and treatment decision making. Physicians should consider factors that can influence patient preference to optimize treatment acceptance and adherence.

Keywords: menstrual cramps, hormonal therapy, intrauterine system, oral regimen, patient preference, treatment administration, treatment attributes

\section{Introduction}

Dysmenorrhea is defined as a severe, painful, cramping sensation in the lower abdomen that is often accompanied by other symptoms, such as sweating, headaches, nausea, vomiting, diarrhea, and tremulousness, all occurring just before or during the menses. ${ }^{1}$ There are two types of dysmenorrhea: primary and secondary. ${ }^{1,2}$ Primary dysmenorrhea refers to pain with no obvious pathological pelvic disease and almost always first occurs in women 20 years of age or younger, once their ovulatory cycles become established. ${ }^{1}$ Secondary dysmenorrhea is caused by underlying pelvic conditions or 
other pathological conditions and is more common in women older than 20 years old. ${ }^{1,2}$

The prevalence of dysmenorrhea can vary considerably, depending on the method of assessment. ${ }^{3}$ In one of the few epidemiological studies conducted in Japan, Ohde et al found that approximately $15.8 \%$ of women aged 18-51 reported experiencing dysmenorrhea. ${ }^{4}$ Another more recent observational study of Japanese women aged 15-49 found that, among those who had visited a gynecologist in the past 3 months for menstrual symptoms, 19.7\% self-reported a diagnosis of dysmenorrhea. ${ }^{5}$ Yet, data from two large-scale cross-sectional survey studies in Japan suggest the prevalence of dysmenorrhea may actually be higher, as menstrual pain was reported by $50.4 \%-77.6 \%$ of women. ${ }^{6,7}$

For women who experience dysmenorrhea, there is a significant effect on their health-related quality of life and daily activities. ${ }^{8-11}$ A prospective observational study of emergency room patients indicated that women who presented with dysmenorrhea and individuals who presented with renal colic reported a comparable level of pain intensity. ${ }^{12}$ Additionally, decrements in health utilities for dysmenorrhea were similar to those associated with chronic migraine. ${ }^{13}$ Thus, the humanistic burden and debilitating effects attributed to dysmenorrhea are substantial.

Dysmenorrhea also poses a considerable economic burden, given its impact on work productivity and health care resource utilization. ${ }^{14,15}$ Dysmenorrhea is responsible for considerable direct and indirect economic losses due to the costs of medications, medical care, and decreased productivity. ${ }^{1}$ Taketani conducted a large survey-based study of 4,230 Japanese women to evaluate the burden of dysmenorrhea and reported that one-third of the women required medical intervention because of their symptoms. ${ }^{16} \mathrm{~A}$ retrospective analysis of Japanese claims data showed that, in the year after diagnosis, women with dysmenorrhea incurred two to three times the direct costs incurred by matched controls. ${ }^{15}$ Furthermore, Tanaka et al reported that the total economic burden to Japanese society associated with menstrual symptoms was approximately $¥ 682.8$ billion (\$8.6 billion US dollars), with work productivity loss accounting for $72 \%$ of the total cost. ${ }^{6}$

There are several treatment options available for dysmenorrhea. NSAIDs have been recommended as a first-line treatment option, although oral, intravaginal, and intrauterine hormonal contraceptives also represent appropriate options, particularly for women who desire contraception along with treatment for their dysmenorrhea. ${ }^{17-19}$ NSAIDs, LEPs, and IUS are primarily recommended in Japan; traditional Chinese medicine and anti-cramp medicine can also be used to treat primary dysmenorrhea. ${ }^{20}$ These treatment options can vary significantly with respect to their mode of administration, dosing characteristics, effectiveness, and safety. In Japan, two kinds of COCs are available on the market: LEPs, which are reimbursed for dysmenorrhea treatment, and other COCs for contraceptive purposes, which are not reimbursed.

A systematic review reported that NSAIDs are highly effective for relieving dysmenorrhea pain, with similar efficacy demonstrated across formulations. However, NSAIDs are ineffective for, or are not tolerated by, approximately $15 \%$ of women with dysmenorrhea. ${ }^{14}$ In a longitudinal cohort study, the use of levonorgestrel-releasing IUSs or COCs was related to a significant decrease over time in dysmenorrhea severity, compared with other methods of contraception (eg, copper intrauterine device, condoms, or barrier methods) or no contraception use. ${ }^{21}$ However, COCs may be contraindicated for women who are at risk for VTE, and levonorgestrelreleasing IUS has been associated with various side effects, such as menstrual irregularity, amenorrhea, ovarian cysts, acne, increases in weight, depressed mood, and a reduction in libido. ${ }^{22,23}$

Despite the sizeable burden attributed to dysmenorrhea and the effectiveness of treatment, this condition is underdiagnosed and undertreated. ${ }^{24}$ Because it is so common, women may erroneously view menstrual pain as being normal and thus may not bring their symptoms to the attention of a health care provider. This idea is supported by a recent prospective, cross-sectional survey of female Jordanian college students in which over three-quarters self-reported experiencing menstrual pain, yet $<10 \%$ of these respondents sought medical treatment. ${ }^{25}$ This is also likely the case in Japan, as cross-sectional population studies have shown that only $12 \%-20 \%$ of women who reported experiencing menstrual pain consulted with a health care provider about treatment. ${ }^{6,16}$ Additionally, religious or cultural beliefs, as well as negative societal attitudes toward menstruation, may not only inhibit women from broaching the topic with their health care provider but also make it less likely that clinicians will raise this issue with their patients. ${ }^{24}$ As such, a better understanding of the factors underlying treatment decisions will be integral to informing strategies to improve treatment rates.

\section{Objective}

Prior research has suggested that adherence can be maximized when treatment is aligned with patient preferences. ${ }^{26}$ Therefore, the aim of this study was to understand how women with dysmenorrhea value different aspects of 
treatments for dysmenorrhea, which can potentially help to improve treatment decision making. Specifically, this study aimed to quantify the trade-offs patients with dysmenorrhea in Japan are willing to make between different product attributes, including mode of administration (oral vs IUS), effectiveness and other patient benefits (chance of symptoms becoming "improved" and chance of reduction in bleeding after 6 months), and treatment tolerability and safety (chance of nausea, chance of weight gain, chance of irregular bleeding, and risk of VTE), by eliciting patient preferences associated with treatments like levonorgestrel-releasing IUS, drospirenone/ethinyl estradiol tablets with a flexible extended regimen, norethisterone/ethinyl estradiol tablets, and dienogest. This study sought to represent potential realworld patient choices as accurately as possible, although limited to the Japanese population.

\section{Methods \\ Pilot testing}

Prior to this patient preference research, a qualitative stage incorporating cognitive interviews $(\mathrm{N}=10$ women with dysmenorrhea) was conducted, which assessed the validity of the survey instrument to be used in the main quantitative study by investigating the appropriateness, clarity, and completeness of the instructions, attributes, levels, and discrete choice questions. Inclusion and exclusion criteria for the interviews were the same as those described in the main study section. Written informed consent was obtained from all pilot test participants. The protocol of the pilot-stage qualitative interviews was reviewed and approved by the Pearl Institutional Review Board (Study Number 16-KANT-129) in Indianapolis, IN, USA. The attributes and levels used in the qualitative interviews were initially developed from clinical data found in literature reviews of clinical trials and other relevant research findings. The cognitive qualitative interviewing helped to further refine the list of attributes and levels to ensure the main study only included those most relevant to the patients when making treatment decisions, while also being easy to understand. After reviewing the results with study team members, the final survey instrument was created for the main observational quantitative study.

\section{Main study}

A DCE method was used. The DCE is a survey approach designed to assess respondents' willingness to accept tradeoffs among hypothetical treatment profiles described by treatment attributes of varying levels. The DCE method is rooted in economic theory and is based on the principle that products can be described by various attributes. In a health care context, the attractiveness of a treatment to patients depends on patients' relative preferences for treatment attributes expressed by their willingness to accept trade-offs among them. Although there are alternatives to eliciting patient preferences (eg, revealed preferences, direct ratings/ rankings, etc), DCE is one of the most common approaches for assessing preferences in a health care context. ${ }^{27}$

To generate the necessary data for the analyses, this study was conducted with 309 women with dysmenorrhea using a web-based survey. These women were recruited from patients who had indicated in a prior survey that they had previously experienced dysmenorrhea. To be included in the study, female respondents had to be aged 18-49 years old, able to read and understand Japanese, and provide informed consent. Additionally, to be eligible to participate, respondents had to have self-reported being diagnosed with dysmenorrhea by a physician, experienced menstrual cramps (dysmenorrhea) in at least one menstrual cycle in the past 6 months, or had menstrual cramps in one of the past three menstrual cycles. Pregnant or postmenopausal women were ineligible for this study. Informed consent was obtained electronically prior to starting the web-based survey.

The survey included a series of preference elicitation questions, each asking respondents to choose between two hypothetical treatments for dysmenorrhea shown side by side (no real treatments or treatment names were used or mentioned in the survey). Predictive probabilities were then estimated to determine whether patients were more likely to choose one hypothetical treatment over another. Each hypothetical treatment alternative shown in the preference elicitation questions was defined by various attributes (eg, mode of administration, chance of symptoms becoming "improved", or risk of VTE), which were developed from prior literature and input from a clinical expert and then refined after patient cognitive interviews. The experimental design (ie, the combination of attributes and levels that were presented to respondents) was developed using the D-optimal algorithm available in SAS version 9.3 using input from the qualitative cognitive interviews, ${ }^{28}$ which helped to determine the wording and the final number of the attributes and levels to be tested in this quantitative study. This method ensured that there were a sufficient number of respondents and number of choice questions presented, that the importance of the contributions of the individual attributes could be isolated from the rest of the (possibly confounding) effects presented simultaneously, and that all attributes and levels were exposed an equal number of times in the DCE. Figure 1 represents an example of a single 
preference elicitation question that was presented to respondents; they were also provided additional information defining irregular bleeding and VTE. After reviewing the information in the two presented profiles, the respondent was asked to select which of the two profiles (Medicine A or B) she would prefer as her dysmenorrhea treatment. In total, respondents were shown nine comparisons to be used in the analyses, plus two additional cards for the purposes of quality control and

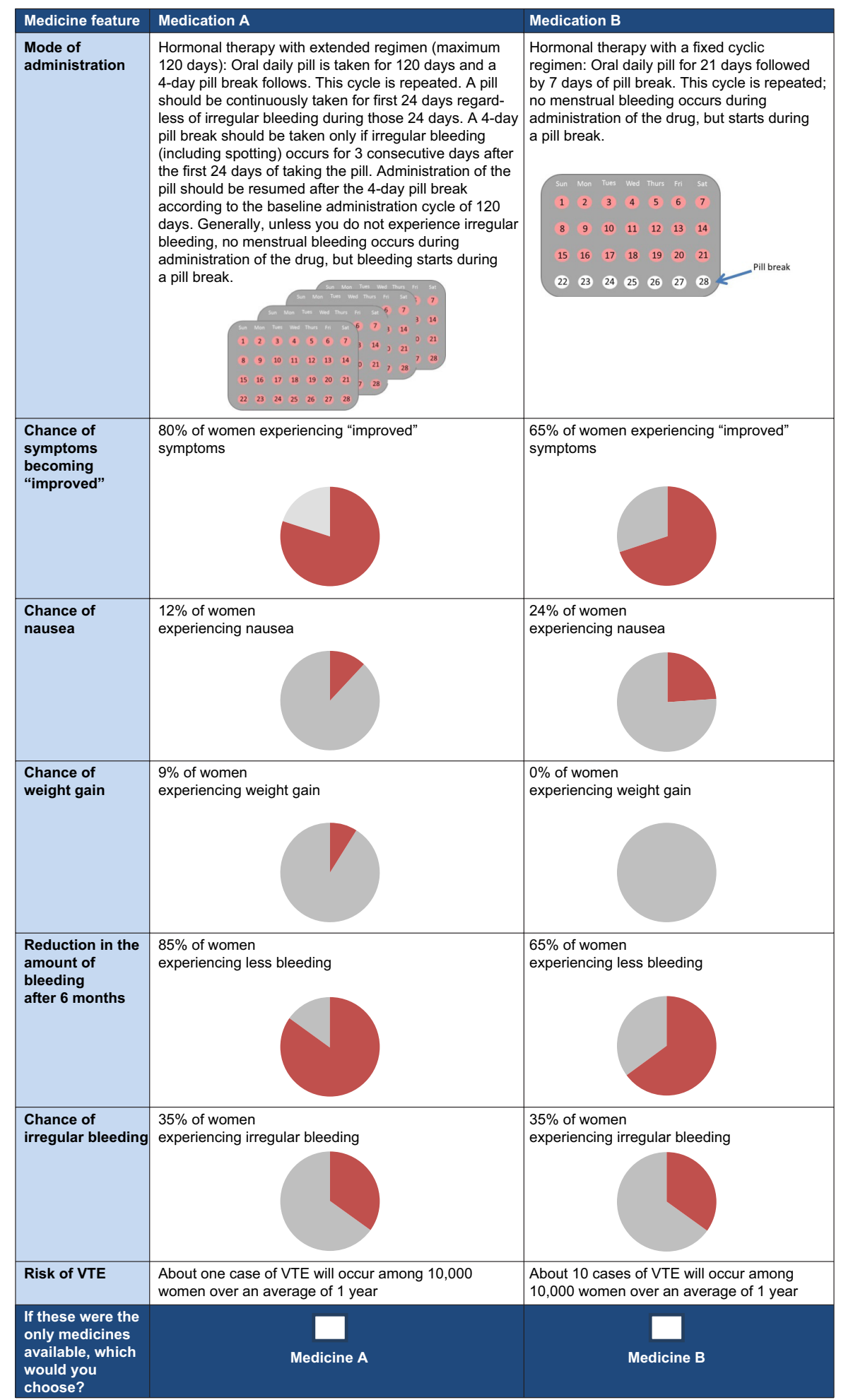

Figure I Example preference elicitation task.

Abbreviation: VTE, venous thromboembolism. 
validity estimation. The main quantitative study protocol was approved by the Ethics Committee of the nonprofit organization, Clinical Research Promotion Network Japan.

\section{Measures}

\section{Demographics}

Demographic information was self-reported by patients and included age, education, marital status, region of residence, employment status, income, and health insurance.

\section{Comorbidities}

Respondents were asked to indicate whether they experienced any of the following comorbidities: headache, lower back pain, lower abdominal pain, migraine, hay fever, nasal allergies, dry eye, acne, chronic constipation, eczema, insomnia, heartburn, anemia, irregular bleeding, nausea, heavy menstrual bleeding, vaginitis, or primary ovarian dysfunction; or whether they were diagnosed with any of the following conditions by a health care provider: endometriosis, endometrial cancer, adenomyosis, uterine fibroids, pulmonary embolism, or retinal thrombosis.

\section{Health history}

Health history variables included self-reported height and weight (used to calculate BMI category), date of dysmenorrhea diagnosis (if applicable), number of menstrual cycles out of the last three that were accompanied by menstrual cramps (dysmenorrhea), number of weeks since last experienced dysmenorrhea, number of days experiencing dysmenorrhea per cycle, number of days experiencing menstrual bleeding per normal menstrual cycle, level of dysmenorrhea pain (using a visual analog scale), any experience of seeking gynecologist consultation, previous and current treatments for dysmenorrhea, and number of previous pregnancies and deliveries.

\section{Work productivity}

Respondents were also asked to self-report on the level of work productivity loss they experienced over the past 3 months and the past 6 months due to dysmenorrhea using a measure that was based on a prior study of dysmenorrhea in Japan. ${ }^{6}$ The specific items and response options were as follows: during the previous 3 (or 6) months, I was absent from work/school work/household chores due to dysmenorrhea symptoms (yes/no; if yes, respondent was asked to report the total number of days); during the previous 3 (or 6) months, I decreased work/school work/household chores volume or time due to dysmenorrhea symptoms (yes/no; if yes, respondent was asked to report the total number of days); during the previous 3 (or 6) months, there were days I had decreased efficiency in work/school work/household chores due to dysmenorrhea symptoms (yes/no; if yes, respondent was asked to report the total number of days).

\section{Attribute categories}

There were seven attribute categories, each with multiple levels: mode of administration (four levels), reduction in the amount of bleeding after 6 months (three levels), chance of symptoms becoming "improved" (three levels), chance of nausea (three levels), chance of weight gain (three levels), chance of irregular bleeding (three levels), and risk of VTE (two levels). A description of attribute categories and levels is shown in Table 1.

\section{Treatment choice}

The primary end point was treatment choice. Specifically, respondents were asked to choose between hypothetical Medicine A and Medicine B.

\section{Analysis}

The analyses were performed using the software package SAS release 9.3 (SAS Institute Inc., Cary, NC, USA) and Sawtooth's Software CBC HB release 4.4.0.

\section{Demographics and baseline characteristics}

The study sample was described with respect to demographics, comorbidities, health history, and work productivity using frequencies and percentages for categorical variables. Means, SDs, medians, and ranges, when appropriate, were reported for continuous variables.

\section{Patient preferences}

The choice data were analyzed using a hierarchical Bayesian logistic regression model. The outcome variable of this model was choice, and the predictor variables were the levels within each attribute (ie, mode of administration, reduction in the amount of bleeding after 6 months, chance of symptoms becoming "improved", chance of nausea, chance of weight gain, chance of irregular bleeding, and risk of VTE). Effects coding parameterization was used for each level within each attribute. Overall goodness-of-fit was examined using the root likelihood, which indicates how much better the model is at predicting the data, compared with chance. The resulting parameter estimate for each attribute level represents the preference weight, which is defined as the marginal utility of a change in the levels tested within a given attribute. Except for mode of administration, interpolations 
Table I Description of attribute categories and levels

\begin{tabular}{|c|c|}
\hline Attribute & Levels \\
\hline \multirow[t]{4}{*}{ Mode of administration } & $\begin{array}{l}\text { Hormonal therapy with extended regimen (maximum I } 20 \text { days); oral daily pill is taken for I } 20 \text { days; } 4 \text {-day pill break } \\
\text { follows; this cycle is repeated; a pill should be continuously taken for first } 24 \text { days regardless of irregular bleeding } \\
\text { during those } 24 \text { days; a 4-day pill break should be taken only if irregular bleeding (including spotting) occurs for } \\
3 \text { consecutive days after the first } 24 \text { days of taking the pill; administration of the pill should be resumed after the 4-day } \\
\text { pill break according to the baseline administration cycle of I } 20 \text { days; generally, unless you do not experience irregular } \\
\text { bleeding, no menstrual bleeding occurs during administration of the drug, but bleeding starts during a pill break }\end{array}$ \\
\hline & $\begin{array}{l}\text { Intrauterine device, long-term hormonal therapy that lasts for } 5 \text { years; do not have to be taken daily; a T-shaped } \\
\text { device is inserted from the vagina at an outpatient clinic (size of device: } 3 \mathrm{~cm} \text { ); after insertion, a periodic check } \\
\text { is needed after } 3,6 \text {, and } 12 \text { months by a doctor; an annual check is also needed when continuing over I year; } \\
\text { when expecting pregnancy, it can be removed from the uterus; generally, no menstrual bleeding occurs during } \\
\text { administration of the drug }\end{array}$ \\
\hline & $\begin{array}{l}\text { Hormonal therapy with a fixed cyclic regimen; oral daily pill is taken for } 2 I \text { days followed by } 7 \text { days of pill break; this } \\
\text { cycle is repeated; no menstrual bleeding occurs during administration of the drug, but starts during a pill break }\end{array}$ \\
\hline & Hormonal therapy; twice-daily pill; no menstrual bleeding occurs during administration of the drug \\
\hline \multirow{3}{*}{$\begin{array}{l}\text { Chance of symptoms } \\
\text { becoming "improved" }\end{array}$} & $50 \%$ of women experiencing "improved" symptoms \\
\hline & $65 \%$ of women experiencing "improved" symptoms \\
\hline & $80 \%$ of women experiencing "improved" symptoms \\
\hline \multirow[t]{3}{*}{ Chance of nausea } & $0 \%$ of women experiencing nausea \\
\hline & $12 \%$ of women experiencing nausea \\
\hline & $24 \%$ of women experiencing nausea \\
\hline \multirow[t]{3}{*}{ Chance of weight gain } & $0 \%$ of women experiencing weight gain \\
\hline & $4 \%$ of women experiencing weight gain \\
\hline & $9 \%$ of women experiencing weight gain \\
\hline \multirow{3}{*}{$\begin{array}{l}\text { Reduction in the amount of } \\
\text { bleeding after } 6 \text { months }\end{array}$} & $65 \%$ of women experiencing less bleeding \\
\hline & $75 \%$ of women experiencing less bleeding \\
\hline & $85 \%$ of women experiencing less bleeding \\
\hline \multirow[t]{3}{*}{ Chance of irregular bleeding } & $1 \%$ of women experiencing irregular bleeding \\
\hline & $35 \%$ of women experiencing irregular bleeding \\
\hline & $70 \%$ of women experiencing irregular bleeding \\
\hline \multirow[t]{2}{*}{ Risk of VTE } & About one case of VTE will occur among I0,000 women over an average of I year \\
\hline & About I0 cases of VTE will occur among 10,000 women over an average of I year \\
\hline
\end{tabular}

Abbreviation: VTE, venous thromboembolism.

were made to determine the marginal utilities for the values contained within the numeric range tested for each attribute. Parameter estimates for the levels tested were reported along with their standard errors, 95\% confidence intervals, and nominal $p$-values.

These parameter estimates were also used to calculate RIs using a sum-of-squares approach. ${ }^{29}$ For each attribute, the regression coefficients for each level of that attribute were squared and summed together. The resulting sums of squares were divided by the attribute-specific degrees of freedom to generate an MSS for each attribute. The RI of each attribute was calculated by dividing the MSS for that attribute by the sum of all MSS values for all attributes. Attributes with higher RIs have a disproportionately larger MSS than other attributes, which is due to larger differences in the observed preference of the individual levels. Ninety-five percent confidence intervals were also reported. RI analyses, as described above, were repeated using data from the subset of respondents who reported having previously used hormonal therapy to treat their dysmenorrhea $(n=85)$ to examine whether results could be replicated among women with prior treatment experience.

\section{Results \\ Demographics and baseline characteristics}

Among the total of 309 women with dysmenorrhea who participated, patients had a mean age of 35.8 years $(\mathrm{SD}=7.0)$ (Table 2), including 71 women in the 18- to 29-year-old age bracket, 135 in the 30- to 39-year-old age bracket, and 103 in the 40- to 49-year-old age bracket. A plurality of respondents reported being employed full time (41.8\%), having a 4-year college degree $(41.8 \%)$, and being from the Kanto region (41.1\%). Most respondents were single/divorced (61.2\%) and reported a household income of $<¥ 7,500,000$ (63.4\%). Similar proportions of respondents indicated having national health insurance (48.9\%) and employees' health insurance (49.2\%). 
Table 2 Demographic characteristics of the full study sample $(\mathrm{N}=309)$

\begin{tabular}{|c|c|}
\hline Variable & Total $(\mathbf{N}=\mathbf{3 0 9})$ \\
\hline Age, mean $\pm S D$ & $35.80 \pm 7.00$ \\
\hline \multicolumn{2}{|l|}{ Age category } \\
\hline $18-29$ years, $n(\%)$ & $7 \mathrm{I}(22.98 \%)$ \\
\hline $30-39$ years, n (\%) & $135(43.69 \%)$ \\
\hline 40-49 years, n (\%) & $103(33.33 \%)$ \\
\hline \multicolumn{2}{|l|}{ Highest level of education } \\
\hline Junior high school, n (\%) & $4(1.29 \%)$ \\
\hline High school, n (\%) & 74 (23.95\%) \\
\hline Vocational school, n (\%) & 44 (14.24\%) \\
\hline 2-year university, n (\%) & 45 (14.56\%) \\
\hline 4-year university, n (\%) & $129(41.75 \%)$ \\
\hline Graduate school, n (\%) & $13(4.21 \%)$ \\
\hline \multicolumn{2}{|l|}{ Marital status } \\
\hline Married/living with partner, n (\%) & $120(38.83 \%)$ \\
\hline Single/divorced, n (\%) & $189(61.17 \%)$ \\
\hline \multicolumn{2}{|l|}{ Region } \\
\hline Hokkaido, n (\%) & 15 (4.85\%) \\
\hline Tohoku, n (\%) & $26(8.41 \%)$ \\
\hline Kanto, n (\%) & $127(4 \mid .10 \%)$ \\
\hline Chubu, n (\%) & 45 (I4.56\%) \\
\hline Kinki, n (\%) & $57(18.45 \%)$ \\
\hline Chugoku, n (\%) & $10(3.24 \%)$ \\
\hline Shikoku, n (\%) & $7(2.27 \%)$ \\
\hline Kyushu, n (\%) & $22(7.12 \%)$ \\
\hline \multicolumn{2}{|l|}{ Employment status } \\
\hline Full time, $\mathrm{n}(\%)$ & 129 (4I.75\%) \\
\hline Self-employed, n (\%) & $17(5.50 \%)$ \\
\hline Part time, $\mathrm{n}(\%)$ & 61 (19.74\%) \\
\hline Homemaker, n (\%) & $5 \mathrm{I}(16.50 \%)$ \\
\hline Retired, n (\%) & $0(0.00 \%)$ \\
\hline Student, n (\%) & $6(1.94 \%)$ \\
\hline Long-term disability, n (\%) & $8(2.59 \%)$ \\
\hline Short-term disability, $\mathrm{n}(\%)$ & I (0.32\%) \\
\hline Not employed, but looking for work, n (\%) & $16(5.18 \%)$ \\
\hline Not employed and not looking for work, n (\%) & $22(7.12 \%)$ \\
\hline \multicolumn{2}{|l|}{ Household income } \\
\hline$<¥ 2,500,000, \mathrm{n}(\%)$ & $44(14.24 \%)$ \\
\hline$¥ 2,500,000-¥ 4,999,999, \mathrm{n}(\%)$ & $86(27.83 \%)$ \\
\hline$¥ 5,000,000-¥ 7,499,999, \mathrm{n}(\%)$ & $66(21.36 \%)$ \\
\hline$¥ 7,500,000-¥ 9,999,999, \mathrm{n}(\%)$ & $39(12.62 \%)$ \\
\hline$¥ 10,000,000-¥ 12,499,999, \mathrm{n}(\%)$ & $11(3.56 \%)$ \\
\hline$¥ 12,500,000-¥ 14,999,999, \mathrm{n}(\%)$ & 9 (2.9।\%) \\
\hline$\geq ¥ 15,000,000, \mathrm{n}(\%)$ & $4(1.29 \%)$ \\
\hline Unknown, n (\%) & $50(16.18 \%)$ \\
\hline \multicolumn{2}{|l|}{ Health insurance } \\
\hline National health insurance, n (\%) & I5I (48.87\%) \\
\hline Employees' health insurance, n (\%) & $152(49.19 \%)$ \\
\hline $\begin{array}{l}\text { None of the above; all treatment costs paid by } \\
\text { patient, } \mathrm{n}(\%)\end{array}$ & $6(1.94 \%)$ \\
\hline
\end{tabular}

Abbreviation: SD, standard deviation.

As shown in Table 3, the most frequently reported dysmenorrhea-related comorbidities currently experienced, experienced in the past, or ever diagnosed were acne (72.8\%), headache (71.5\%), and lower back pain (59.6\%). In contrast,
Table 3 Dysmenorrhea-related comorbidities for the full study sample $(\mathrm{N}=309)$

\begin{tabular}{|c|c|}
\hline Variable & Total $(\mathbf{N}=309)$ \\
\hline \multicolumn{2}{|c|}{$\begin{array}{l}\text { Conditions that are currently being experienced or } \\
\text { were experienced in the past }\end{array}$} \\
\hline Acne, n (\%) & 225 (72.82\%) \\
\hline Headache, n (\%) & $221(71.52 \%)$ \\
\hline Lower back pain, $\mathrm{n}(\%)$ & $184(59.55 \%)$ \\
\hline Nausea, n (\%) & 170 (55.02\%) \\
\hline Lower abdominal pain, n (\%) & $166(53.72 \%)$ \\
\hline Migraine, n (\%) & $154(49.84 \%)$ \\
\hline Anemia, n (\%) & I5I (48.87\%) \\
\hline Nasal allergies, n (\%) & 140 (45.3 I\%) \\
\hline Eczema, n (\%) & $126(40.78 \%)$ \\
\hline Hay fever, n (\%) & $124(40.13 \%)$ \\
\hline Heartburn, n (\%) & 119 (38.5 I\%) \\
\hline Dry eye, n (\%) & I I 7 (37.86\%) \\
\hline Irregular bleeding, n (\%) & $106(34.30 \%)$ \\
\hline Chronic constipation, $\mathrm{n}(\%)$ & $98(31.72 \%)$ \\
\hline Insomnia, $\mathrm{n}(\%)$ & $93(30.10 \%)$ \\
\hline Heavy menstrual bleeding, $\mathrm{n}(\%)$ & $56(18.12 \%)$ \\
\hline Vaginitis, $\mathrm{n}(\%)$ & $39(12.62 \%)$ \\
\hline Primary ovarian dysfunction, $\mathrm{n}(\%)$ & I $(0.32 \%)$ \\
\hline None of the above, $\mathrm{n}(\%)$ & $8(2.59 \%)$ \\
\hline \multicolumn{2}{|c|}{ Conditions that were diagnosed by a health care } \\
\hline \multicolumn{2}{|c|}{ provider } \\
\hline Endometriosis, n (\%) & $34(11.00 \%)$ \\
\hline Uterine fibroids, n (\%) & $31(10.03 \%)$ \\
\hline Adenomyosis, $\mathrm{n}(\%)$ & $8(2.59 \%)$ \\
\hline Endometrial cancer, n (\%) & I (0.32\%) \\
\hline Pulmonary embolism, n (\%) & $0(0.00 \%)$ \\
\hline Retinal thrombosis, $\mathrm{n}(\%)$ & $0(0.00 \%)$ \\
\hline
\end{tabular}

those comorbidities reported least often by participants included primary ovarian dysfunction and endometrial cancer (for each, $0.3 \%$ ), as well as pulmonary embolism and retinal thrombosis (for each, $0.0 \%$ ).

Patients who had been diagnosed ( $\mathrm{n}=103$ [33.3\%]) with dysmenorrhea were diagnosed, on average, 11.0 years prior $(\mathrm{SD}=8.0)$ (Table 4). Almost two-thirds (63.4\%) were of normal weight. Approximately three-quarters of respondents (74.4\%) had never been pregnant, but among those who had previously been pregnant, a plurality $(39.2 \%)$ reported giving birth one time. Of the last three menstrual cycles, most respondents reported experiencing dysmenorrhea in all three cycles (71.2\%). Dysmenorrhea was last experienced a median of 3.0 (range $=1.0-26.0$ ) weeks prior and was experienced a median of 2.0 (range $=0.0-28.0$ ) days per menstrual cycle. On a scale of 0 (no pain) to 10 (the worst imaginable pain), dysmenorrhea pain in the typical menstrual cycle and in the most recent menstrual cycle was rated a mean of $6.2(\mathrm{SD}=2.1)$ and $5.8(\mathrm{SD}=2.2)$, respectively. Approximately half of the sample was currently being 
Table 4 Health history for the full study sample $(\mathrm{N}=309)$

\begin{tabular}{|c|c|}
\hline Variable & Total $(\mathbf{N}=309)$ \\
\hline $\mathrm{BMI}$, mean $\pm \mathrm{SD}$ & $21.00 \pm 4.00$ \\
\hline \multicolumn{2}{|l|}{ BMI, category } \\
\hline Underweight, n (\%) & $75(24.27 \%)$ \\
\hline Normal weight, n (\%) & $196(63.43 \%)$ \\
\hline Overweight, n (\%) & $26(8.41 \%)$ \\
\hline Obese, n (\%) & $12(3.88 \%)$ \\
\hline $\begin{array}{l}\text { Years since diagnosed with dysmenorrhea, if } \\
\text { applicable }(n=103) \text {, mean } \pm S D\end{array}$ & I I.02士7.99 \\
\hline \multicolumn{2}{|l|}{$\begin{array}{l}\text { Number of the last three menstrual cycles } \\
\text { accompanied by dysmenorrhea }\end{array}$} \\
\hline $0, \mathrm{n}(\%)$ & $15(4.85 \%)$ \\
\hline $\mathrm{I}, \mathrm{n}(\%)$ & $31(10.03 \%)$ \\
\hline $2, \mathrm{n}(\%)$ & $43(13.92 \%)$ \\
\hline $3, \mathrm{n}(\%)$ & $220(71.20 \%)$ \\
\hline $\begin{array}{l}\text { Number of weeks since last experienced } \\
\text { dysmenorrhea, mean } \pm S D\end{array}$ & $\begin{array}{l}4.33 \pm 5.00 ; \text { median } 3.0 ; \\
\text { range } 1.0-26.0\end{array}$ \\
\hline $\begin{array}{l}\text { Number of days typically have menstrual } \\
\text { bleeding during a normal menstrual cycle }\end{array}$ & $\begin{array}{l}6.60 \pm 5.10 ; \text { median } 5.0 ; \\
\text { range } 0.0-33.0\end{array}$ \\
\hline $\begin{array}{l}\text { Number of days experience dysmenorrhea } \\
\text { per menstrual cycle, mean } \pm S D\end{array}$ & $\begin{array}{l}2.7 I \pm 2.48 ; \text { median } 2.0 ; \\
\text { range } 0.0-28.0\end{array}$ \\
\hline \multicolumn{2}{|l|}{$\begin{array}{l}\text { Level of dysmenorrhea pain (from " } 0 \text { " no pain } \\
\text { to "I0" the worst imaginable pain) }\end{array}$} \\
\hline $\begin{array}{l}\text { Pain level during typical menstrual cycle, } \\
\text { mean } \pm S D\end{array}$ & $6.18 \pm 2.12$ \\
\hline $\begin{array}{l}\text { Pain level during most recent menstrual } \\
\text { cycle, mean } \pm S D \text { ) }\end{array}$ & $5.81 \pm 2.23$ \\
\hline \multicolumn{2}{|l|}{ Number of times been pregnant } \\
\hline $0, \mathrm{n}(\%)$ & $230(74.43 \%)$ \\
\hline I, n (\%) & $38(12.30 \%)$ \\
\hline $2, \mathrm{n}(\%)$ & 25 (8.09\%) \\
\hline $3, \mathrm{n}(\%)$ & $9(2.91 \%)$ \\
\hline$\geq 4, \mathrm{n}(\%)$ & $7(2.27 \%)$ \\
\hline \multicolumn{2}{|l|}{ Number of times given birth, if applicable $(n=79)$} \\
\hline $0, \mathrm{n}(\%)$ & $25(31.65 \%)$ \\
\hline $\mathrm{I}, \mathrm{n}(\%)$ & 31 (39.24\%) \\
\hline $2, \mathrm{n}(\%)$ & $19(24.05 \%)$ \\
\hline $3, \mathrm{n}(\%)$ & $4(5.06 \%)$ \\
\hline Ever seen a gynecologist, n (\%) & $25 I(81.23 \%)$ \\
\hline \multicolumn{2}{|l|}{ Currently receiving treatment for } \\
\hline \multicolumn{2}{|l|}{ dysmenorrhea (including over-the-counter) } \\
\hline Yes, n (\%) & I5I (48.87\%) \\
\hline No, n (\%) & $158(5 \mid .13 \%)$ \\
\hline \multicolumn{2}{|l|}{$\begin{array}{l}\text { Treatments currently receiving for } \\
\text { dysmenorrhea }(n=|5|)\end{array}$} \\
\hline Over-the-counter pain medications, n (\%) & $88(58.28 \%)$ \\
\hline Prescription pain medications, n (\%) & $43(28.48 \%)$ \\
\hline LEPs/low-dose oral contraceptives, n (\%) & $29(19.21 \%)$ \\
\hline $\begin{array}{l}\text { Other type of dysmenorrhea treatments, } \\
\mathrm{n}(\%)\end{array}$ & $23(15.23 \%)$ \\
\hline Traditional Chinese medicine, n (\%) & $19(12.58 \%)$ \\
\hline Iron supplements, n (\%) & $7(4.64 \%)$ \\
\hline Sleeping pills, n (\%) & $3(1.99 \%)$ \\
\hline Other drugs, n (\%) & $3(1.99 \%)$ \\
\hline Progestins, n (\%) & $2(1.32 \%)$ \\
\hline Intrauterine system/device, n (\%) & $0(0.00 \%)$ \\
\hline Medium-dose hormonal combinations, n (\%) & I (0.66\%) \\
\hline I do not know/l cannot remember, n (\%) & $5(3.31 \%)$ \\
\hline
\end{tabular}

Table 4 (Continued)

\begin{tabular}{ll}
\hline Variable & Total (N=309) \\
\hline Treatments ever received for dysmenorrhea & \\
Over-the-counter pain medications, $\mathrm{n}(\%)$ & $169(54.69 \%)$ \\
Prescription pain medications, $\mathrm{n}(\%)$ & $97(31.39 \%)$ \\
LEPs/low-dose oral contraceptives, $\mathrm{n}(\%)$ & $75(24.27 \%)$ \\
Traditional Chinese medicine, $\mathrm{n}(\%)$ & $68(22.01 \%)$ \\
Other type of dysmenorrhea treatments, & $66(21.36 \%)$ \\
$\mathrm{n}(\%)$ & \\
Iron supplements, $\mathrm{n}(\%)$ & $22(7.12 \%)$ \\
Medium-dose hormonal combinations, $\mathrm{n}(\%)$ & $14(4.53 \%)$ \\
Sleeping pills, $\mathrm{n}(\%)$ & $14(4.53 \%)$ \\
Other drugs, $\mathrm{n}(\%)$ & $12(3.88 \%)$ \\
Progestins, $\mathrm{n}(\%)$ & $7(2.27 \%)$ \\
Intrauterine system/device, $\mathrm{n}(\%)$ & $\mathrm{I}(0.32 \%)$ \\
I do not know/l cannot remember, $\mathrm{n}(\%)$ & $35(\mathrm{II.33 \% )}$ \\
\hline
\end{tabular}

Abbreviations: BMI, body mass index; LEP, low-dose estrogen progestin; SD, standard deviation.

treated for dysmenorrhea (48.9\%). The most commonly reported treatments ever received for dysmenorrhea were OTC (54.7\%) and prescription pain medications (31.4\%). The treatments least often reported were IUS $(0.3 \%)$ and progestins (2.3\%).

As depicted in Table 5, respondents reported being approximately half as efficient (mean $=53.3 \%, \mathrm{SD}=22.4$ ) at work/school/household chores due to dysmenorrhea, compared with their level of efficiency on a normal day (ie, a day with $100 \%$ efficiency). Sizeable minorities of respondents indicated having missed (18.8\%), reduced volume $(22.3 \%)$, or reduced efficiency $(36.9 \%)$ in work/ school/household chores in the past 6 months. Among those who reported having missed work/school/household chores in the past 6 months, a median of 4.0 (range $=1.0-60.0$ ) days were missed. For those who reduced their work/ school/household chores volume in the past 6 months, volume was reduced for a median of 6.0 (range $=1.0-58.0$ ) days. A median of 8.5 (range $=1.0-60.0$ ) days of reduced efficiency at work/school/household chores in the past 6 months was reported.

\section{Patient preferences: total sample}

Over the range of attributes and levels included in the survey, mode of administration ( $\mathrm{RI}=49.8 \%$ ) was the most strongly associated with treatment preference, followed by chance of irregular bleeding $(\mathrm{RI}=17.3 \%)$, chance of nausea $(\mathrm{RI}=13.8 \%)$, and chance of symptoms becoming "improved" $(\mathrm{R}=10.1 \%)$. Risk of VTE (RI=5.8\%), chance of weight gain ( $\mathrm{RI}=2.4 \%)$, and reduction in bleeding after 6 months $(\mathrm{RI}=0.8 \%)$ were the most weakly associated with preference. This is further 
Table 5 Work productivity for the full sample $(\mathrm{N}=309)$

\begin{tabular}{|c|c|}
\hline Variable & Total $(\mathbf{N}=309)$ \\
\hline \multicolumn{2}{|l|}{ Missed work/school/household chores in past } \\
\hline \multicolumn{2}{|l|}{6 months } \\
\hline Yes, n (\%) & $58(18.77 \%)$ \\
\hline No, n (\%) & $251(81.23 \%)$ \\
\hline \multicolumn{2}{|l|}{ Missed work/school/household chores in past } \\
\hline \multicolumn{2}{|l|}{3 months $(n=58)$} \\
\hline Yes, n (\%) & $47(81.03 \%)$ \\
\hline No, n (\%) & II (I8.97\%) \\
\hline \multirow{2}{*}{\multicolumn{2}{|c|}{$\begin{array}{l}\text { Reduced work/school/household chores volume } \\
\text { in past } 6 \text { months }\end{array}$}} \\
\hline & \\
\hline Yes, n (\%) & 69 (22.33\%) \\
\hline No, n (\%) & $240(77.67 \%)$ \\
\hline \multirow{2}{*}{\multicolumn{2}{|c|}{$\begin{array}{l}\text { Reduced work/school/household chores volume } \\
\text { in past } 3 \text { months }(n=69)\end{array}$}} \\
\hline & \\
\hline Yes, n (\%) & $65(94.20 \%)$ \\
\hline No, n (\%) & $4(5.80 \%)$ \\
\hline \multicolumn{2}{|l|}{$\begin{array}{l}\text { Reduced efficiency in work/school/household } \\
\text { chores in past } 6 \text { months }\end{array}$} \\
\hline Yes, n (\%) & I 4 (36.89\%) \\
\hline No, n (\%) & $195(63.11 \%)$ \\
\hline \multicolumn{2}{|l|}{$\begin{array}{l}\text { Reduced efficiency in work/school/household } \\
\text { chores in past } 3 \text { months }(n=1 \mid 4)\end{array}$} \\
\hline Yes, n (\%) & $109(95.61 \%)$ \\
\hline No, n (\%) & $5(4.39 \%)$ \\
\hline $\begin{array}{l}\text { Number of days missed from work/school/ } \\
\text { household chores in past } 6 \text { months }(n=58) \text {, } \\
\text { mean } \pm S D\end{array}$ & $\begin{array}{l}8.02 \pm 9.79 ; \text { median } 4.0 ; \\
\text { range } 1.0-60.0\end{array}$ \\
\hline $\begin{array}{l}\text { Number of days missed from work/school/ } \\
\text { household chores in past } 3 \text { months }(n=47) \text {, } \\
\text { mean } \pm S D\end{array}$ & $\begin{array}{l}5.49 \pm 6.22 ; \text { median } 3.0 ; \\
\text { range } 1.0-35.0\end{array}$ \\
\hline $\begin{array}{l}\text { Number of days reduced work/school/ } \\
\text { household chores volume in past } 6 \text { months } \\
(n=69) \text {, mean } \pm S D\end{array}$ & $\begin{array}{l}7.1 \mathrm{I} \pm 7.78 \text {; median } 6.0 \text {; } \\
\text { range } 1.0-58.0\end{array}$ \\
\hline $\begin{array}{l}\text { Number of days reduced work/school/ } \\
\text { household chores volume in past } 3 \text { months } \\
(n=65) \text {, mean } \pm S D\end{array}$ & $\begin{array}{l}3.98 \pm 3.00 ; \text { median } 3.0 ; \\
\text { range } 1.0-15.0\end{array}$ \\
\hline $\begin{array}{l}\text { Number of days reduced efficiency in work/ } \\
\text { school/household chores in past } 6 \text { months } \\
(n=I \mid 4) \text {, mean } \pm S D\end{array}$ & $\begin{array}{l}10.6 I \pm 9.06 ; \text { median } \\
8.5 ; \text { range } 1.0-60.0\end{array}$ \\
\hline $\begin{array}{l}\text { Number of days reduced efficiency in work/ } \\
\text { school/household chores in past } 3 \text { months } \\
(n=109) \text {, mean } \pm S D\end{array}$ & $\begin{array}{l}5.72 \pm 5.07 ; \text { median } 3.0 ; \\
\text { range } 1.0-30.0\end{array}$ \\
\hline $\begin{array}{l}\text { Percentage level of efficiency at work/school/ } \\
\text { household chores due to dysmenorrhea, } \\
\text { compared to normal day, mean } \pm S D\end{array}$ & $53.29 \pm 22.43$ \\
\hline
\end{tabular}

Note: In those cases in which data were based upon less than the full sample of $\mathrm{N}=309$, the relevant sample size is provided in parentheses.

Abbreviation: SD, standard deviation.

illustrated in the RI weights shown in Figure 2. The preference weights and their $95 \%$ confidence intervals are also displayed in Figure 3. The greater the vertical changes evidenced within an attribute (as illustrated for mode of administration and chance of irregular bleeding), the stronger the relationship between that attribute and treatment choice.
The hierarchical Bayesian logistic regression model results are reported in Table 6. All levels of all attributes were nominally significantly associated with choice $(p<0.05$ for all). Respondents had nominally significantly higher odds of preferring oral treatments: for twice-daily regimen, $\mathrm{OR}=4.90$; for once-daily fixed cyclic regimen, $\mathrm{OR}=4.20$; and for once-daily flexible extended regimen, $\mathrm{OR}=2.44$; whereas for IUS, OR=0.02 (the reference group was the mean level of the attribute; $p<0.001$ for all).

\section{Patient preferences: prior hormonal therapy users}

Among respondents with prior hormonal therapy use $(n=85)$, the most common treatment ever received for dysmenorrhea was a low-dose hormonal combination (in Japan, for dysmenorrhea treatment, this refers only to LEPs/low-dose oral contraceptives; $88.2 \%$ ). The same pattern of preference results was seen among the subset of women with prior hormonal therapy experience as was observed in the total sample. Specifically, mode of administration ( $\mathrm{RI}=49.6 \%$ ) was the most strongly associated with treatment preference, followed by chance of irregular bleeding $(\mathrm{RI}=17.7 \%)$, chance of nausea ( $\mathrm{RI}=12.6 \%$ ), and chance of symptoms becoming "improved" ( $\mathrm{RI}=10.2 \%)$. Risk of VTE $(\mathrm{RI}=6.9 \%)$, chance of weight gain $(\mathrm{RI}=2.5 \%)$, and reduction in bleeding after 6 months $(\mathrm{RI}=0.5 \%)$ were the most weakly associated with preference (data not shown). All levels of all attributes were nominally significantly associated with choice $(p<0.05$ for all), except for $35 \%$ chance of irregular bleeding, which was only marginally significant ( $p=0.096)$. As with the total sample, respondents had nominally significantly higher odds of preferring orals: for twice-daily regimen, $\mathrm{OR}=4.20$; for once-daily fixed cyclic regimen, $\mathrm{OR}=3.97$; and for oncedaily flexible extended regimen, $\mathrm{OR}=2.54$; whereas for IUS, $\mathrm{OR}=0.02$ (the reference group was the mean level of the attribute; $p<0.001$ for all) (data not shown).

\section{Discussion}

The current study examined dysmenorrhea treatment preferences among a relatively broad range of women in Japan. The majority of participants did not have prior hormonal therapy experience and were not currently planning on becoming pregnant. By including respondents who selfreported having a dysmenorrhea diagnosis or experiencing symptoms of dysmenorrhea, as well as those who were not anticipating pregnancy (and were therefore presumably open to contraceptive treatment options), the sample was selected 


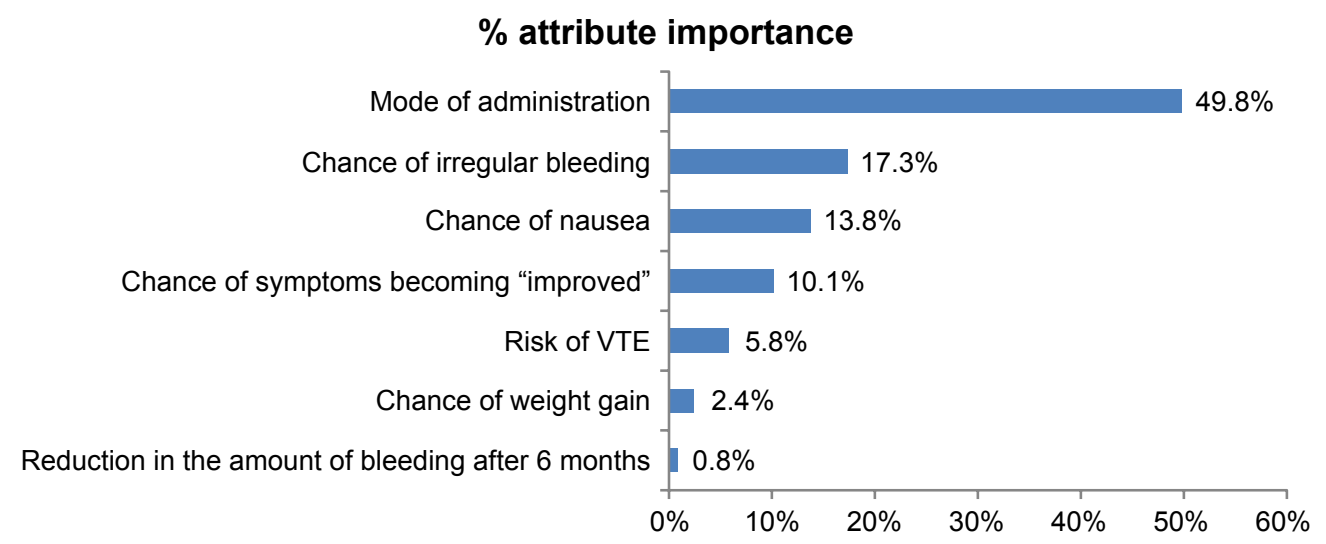

Figure 2 Relative importance of treatment attributes for the full study sample $(\mathrm{N}=309)$. Abbreviation: VTE, venous thromboembolism.

to represent those who could seriously consider initiating the types of treatment options presented, as opposed to those for whom these options (and their corresponding preferences) might be irrelevant. This approach helped to enhance the ecological validity of our results.

In summary, results revealed that mode of administration factored heavily in dysmenorrhea treatment preferences. Specifically, women of reproductive age significantly preferred oral medications, with preferences being highest for twice-daily (no menstrual bleeding occurs during administration of the drug) and once-daily fixed cyclic regimens (with 7 days of pill break; no menstrual bleeding occurs during administration of the drug, but starts during a pill break). These findings suggest that women with dysmenorrhea may prefer regular, simple treatment regimens. These preferences may have important implications not only for treatment decision making but also for treatment adherence in the real world, as a prior study has shown that risks for nonadherence

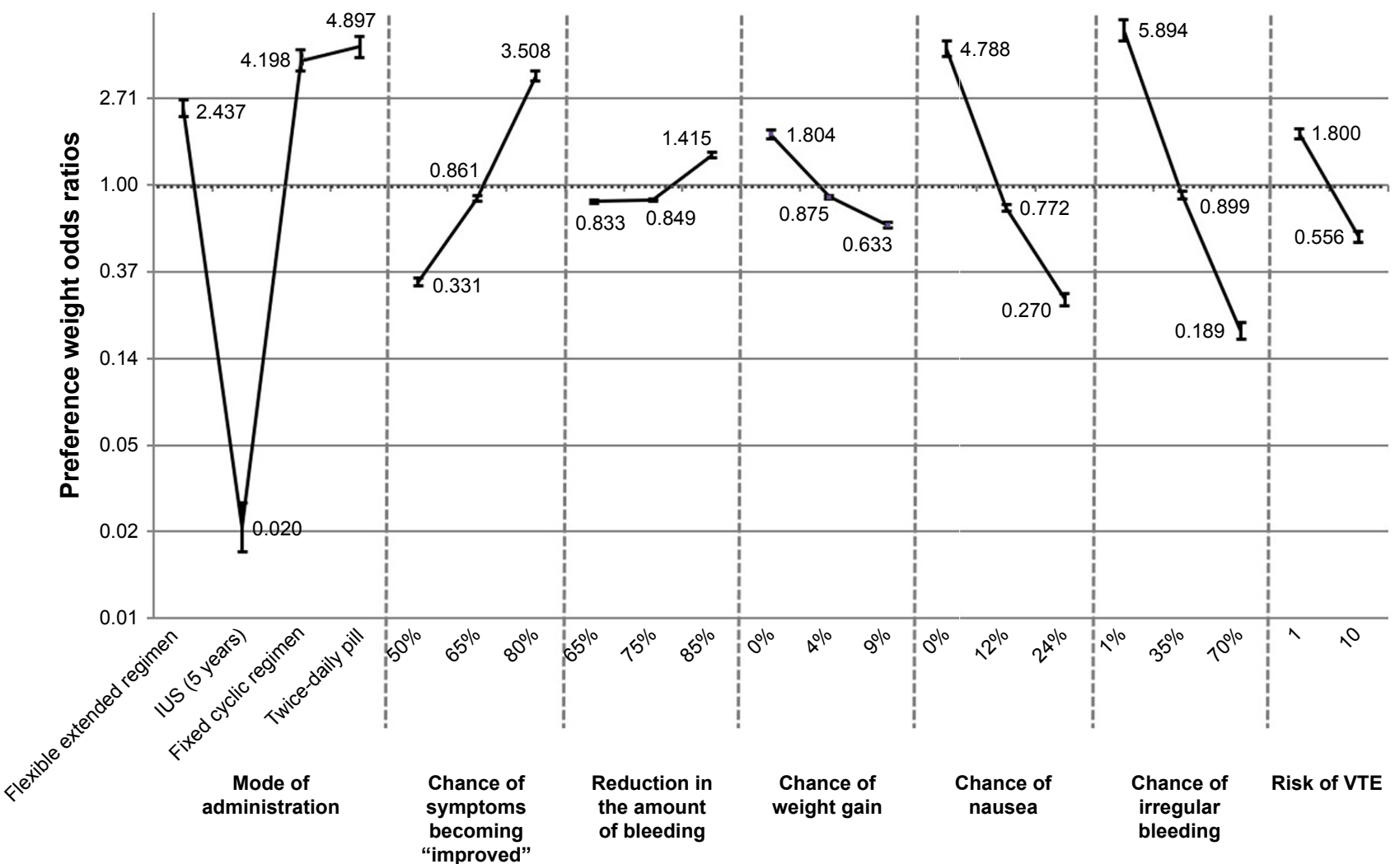

Figure 3 Patient preference weights exponentiated, with 95\% confidence intervals $(\mathrm{N}=309)$. Abbreviations: IUS, intrauterine system; VTE, venous thromboembolism. 
Table 6 Regression model results predicting medication choice for the full study sample $(\mathrm{N}=309)$

\begin{tabular}{|c|c|c|c|c|c|c|}
\hline Attribute & Levels & b & SE & $\mathbf{Z}$ & $p$-value & OR \\
\hline \multirow[t]{5}{*}{ Mode of administration } & Hormonal therapy with extended regimen (maximum 120 days) & 0.89 & 0.05 & 18.16 & $<0.001$ & 2.437 \\
\hline & Intrauterine device, long-term hormonal therapy which lasts & -3.91 & 0.14 & -27.32 & $<0.001$ & 0.020 \\
\hline & for 5 years; do not have to be taken daily & & & & & \\
\hline & Hormonal therapy with a fixed cyclic regimen & 1.43 & 0.06 & 22.43 & $<0.001$ & 4.198 \\
\hline & Hormonal therapy: twice-daily pill & 1.59 & 0.06 & 26.05 & $<0.001$ & 4.897 \\
\hline Chance of symptoms & $50 \%$ of women experiencing "improved" symptoms & -1.11 & 0.02 & -44.59 & $<0.001$ & 0.331 \\
\hline \multirow[t]{2}{*}{ becoming "improved" } & $65 \%$ of women experiencing "improved" symptoms & -0.15 & 0.02 & -9.04 & $<0.001$ & 0.861 \\
\hline & $80 \%$ of women experiencing "improved" symptoms & 1.26 & 0.03 & 41.41 & $<0.001$ & 3.508 \\
\hline Reduction in the amount & $65 \%$ of women experiencing less bleeding & -0.18 & 0.01 & -22.51 & $<0.001$ & 0.833 \\
\hline of bleeding after 6 & $75 \%$ of women experiencing less bleeding & -0.16 & 0.01 & -21.55 & $<0.001$ & 0.849 \\
\hline months & $85 \%$ of women experiencing less bleeding & 0.35 & 0.02 & 22.07 & $<0.001$ & 1.415 \\
\hline \multirow[t]{3}{*}{ Chance of nausea } & $0 \%$ of women experiencing nausea & 1.57 & 0.05 & 34.33 & $<0.001$ & 4.788 \\
\hline & $12 \%$ of women experiencing nausea & -0.26 & 0.02 & -13.66 & $<0.001$ & 0.772 \\
\hline & $24 \%$ of women experiencing nausea & $-\mid .31$ & 0.04 & -35.29 & $<0.001$ & 0.270 \\
\hline \multirow[t]{3}{*}{ Chance of weight gain } & $0 \%$ of women experiencing weight gain & 0.59 & 0.02 & 23.82 & $<0.001$ & 1.804 \\
\hline & $4 \%$ of women experiencing weight gain & -0.13 & 0.01 & -12.45 & $<0.001$ & 0.875 \\
\hline & $9 \%$ of women experiencing weight gain & -0.46 & 0.02 & -25.59 & $<0.001$ & 0.633 \\
\hline Chance of irregular & I\% of women experiencing irregular bleeding & 1.77 & 0.06 & 28.56 & $<0.001$ & 5.894 \\
\hline \multirow[t]{2}{*}{ bleeding } & $35 \%$ of women experiencing irregular bleeding & -0.11 & 0.02 & -4.39 & $<0.001$ & 0.899 \\
\hline & $70 \%$ of women experiencing irregular bleeding & -1.67 & 0.05 & -33.84 & $<0.001$ & 0.189 \\
\hline \multirow[t]{2}{*}{ Risk of VTE } & $\begin{array}{l}\text { About one case of VTE will occur among 10,000 women } \\
\text { over an average of I year }\end{array}$ & 0.59 & 0.03 & 19.97 & $<0.001$ & 1.800 \\
\hline & $\begin{array}{l}\text { About I0 cases of VTE will occur among I0,000 women } \\
\text { over an average of I year }\end{array}$ & -0.59 & 0.03 & -19.97 & $<0.001$ & 0.556 \\
\hline
\end{tabular}

Notes: ORs reflect the relative odds of selecting a given level within an attribute vs the mean level for that attribute. $b$ : point estimates of part-worth utilities. Abbreviations: OR, odds ratio; SE, standard error; VTE, venous thromboembolism.

and discontinuation may increase if prescribed medications are misaligned with patient preferences. ${ }^{26}$

Chance of irregular bleeding and chance of nausea were also shown to be important factors for patient preference. It would be prudent for clinicians to take these findings into account when discussing treatment options with patients. In particular, nausea is commonly experienced by those with dysmenorrhea, ${ }^{14}$ and irregular bleeding has been cited as a reason why some women choose to discontinue treatment with COCs. ${ }^{30}$ Results also demonstrated that risk of VTE was weakly associated with patient preference. While the link between estrogen-containing COCs and VTE has been well established, ${ }^{31}$ it is unclear whether patients are aware of the potential risk. A disconnect between patient preference and risk of VTE may present an opportunity for health care providers to further educate their patients on this issue, which can help to ensure patients make informed decisions.

The same results were replicated with a small subsample of women with prior hormonal therapy experience $(n=85$, data not shown), although few (1.2\%) had ever used an IUS. The findings from these supplementary analyses suggest that preferences are not altered noticeably, given the experience. Thus, these analyses provided greater confidence in the initial pattern of findings, as previous experience with hormonal therapy could be reasonably excluded as an alternative explanation.

Ultimately, dysmenorrhea largely goes undiagnosed and untreated, despite the substantial humanistic and economic burden attributed to this condition. ${ }^{14,24}$ Improving dysmenorrhea management will be essential to addressing this burden, given treatment is associated with better health-related quality of life and indirect cost savings. ${ }^{5}$ A prior meta-analysis of clinical trial data across multiple disease conditions demonstrated that the alignment of treatment with patient preference was related to higher treatment satisfaction, a greater likelihood of treatment completion, and better clinical outcomes. ${ }^{32}$ Therefore, patient preferences will play an integral role in devising strategies to enhance dysmenorrhea management.

Research suggests that women often inaccurately believe menstrual pain is normal, and as a result, may subsequently forgo treatment. ${ }^{5,14,24}$ However, those women who do receive treatment tend to be satisfied. For example, a systematic review reported that satisfaction was high for COCs with an extended or continuous regimen, although there was also evidence indicating some users discontinued treatment due to irregular bleeding. ${ }^{30} \mathrm{~A}$ prospective longitudinal observational 
study reported that a pill containing estradiol valerate and dienogest was associated with better outcomes (eg, shorter period, less bleeding, and less menstrual pain) and higher user satisfaction than a progestogen-only pill, with discontinuation rates of $20 \%$ and $26 \%$, respectively. ${ }^{33}$ A systematic review of research on levonorgestrel-releasing IUS found that over three-quarters of users reported symptom improvement and were satisfied with treatment. ${ }^{23}$ Of direct relevance to satisfaction, the current study is one of the first to provide results on the treatment preferences of women with dysmenorrhea. Collectively, data on patient preferences for dysmenorrhea treatments will be vital in fostering greater physician-patient communication about treatment decision making, which can help to optimize treatment.

\section{Limitations}

There are several forms of selection bias, which are acknowledged but unavoidable. For example, it is quite possible that the patients included in this study were healthier or had better functioning compared with other dysmenorrhea patients. Additionally, the study was limited to internet users, and women without access to either the internet or the patient panels were not represented. These factors could have been confounded with treatment preferences. Furthermore, the study task was a simplified representation of a potential realworld choice among dysmenorrhea treatments. These choices were intended to simulate possible treatment decisions, but obviously they would not have the same clinical, financial, or emotional consequences of actual decisions that may be affected by preferences. Moreover, there are a multitude of other factors (eg, presentation of treatment options by a physician, internet search, family/friend opinion, etc) that would be present in a real-world choice selection that could not be reasonably accounted for in our controlled study. As a result, preferences, when patients are confronted with a real choice, may differ from our DCE results. However, potential hypothetical bias was limited as much as possible by constructing choice questions that mimicked realistic clinical choices and were consistent with prior research evidence. Although not central to the research questions, a few of our potential covariates (eg, comorbidities) were self-reported by respondents without clinical verification, thereby potentially introducing additional measurement error into the assessment of these variables.

Due to sample selection during recruitment, the results may not be generalizable to the entire dysmenorrhea population. By using age-based quotas and selecting patients from different geographic locations, we attempted to provide a sample that was representative of patients with dysmenorrhea in Japan. However, no specific sampling frame was imposed, and we could not control the precise ratio of subgroups that may appear in the dysmenorrhea population.

Respondents' demographic characteristics and health history were reported, which allowed for these factors to be compared with other studies to better ascertain the representativeness of the sample and the generalizability of the findings. The age distribution in the current study was highly similar to other cross-sectional survey studies on dysmenorrhea in Japan. ${ }^{5-7,15}$ A larger proportion of participants in this study were employed (full time, part time, or self-employed) than in the two studies that reported on this variable, ${ }^{5,6}$ although the annual household income distribution in the current study was in line with a study by Tanaka et al. ${ }^{5}$ Most participants in this study had normal BMI, whereas the majority of participants in a study by Nohara et al were underweight. ${ }^{7}$ Additionally, OTC analgesic use in this study was moderately higher than that of outpatients, as well as women in the general population, with dysmenorrhea in studies by Tanaka et al, 5,6 yet much lower than the OTC analgesic use reported by women with dysmenorrhea who did not seek medical treatment. ${ }^{5}$ Hence, in general, participant demographics in the present study were fairly comparable to those reported in other studies, which provides some support for the representativeness of the sample. Nevertheless, appropriate caution should be exercised in generalizing the findings more broadly, given there were modest differences between studies in sample health characteristics and treatment use.

\section{Conclusion}

Mode of administration factored heavily in dysmenorrhea treatment preferences; Japanese women of reproductive age significantly preferred oral treatments, with preferences being highest for twice-daily and once-daily fixed cyclic regimens. The most important factors driving preferences were the chance of irregular bleeding and the chance of nausea.

These findings help illuminate the perspective of women with dysmenorrhea, which can, in turn, help inform physician-patient communication and treatment decision making. It is important for physicians to provide patients with an explanation about dysmenorrhea treatments and to consider factors that may influence patient preference to ensure greater treatment acceptance and adherence.

\section{Data sharing statement}

Availability of the data underlying this publication will be determined according to Bayer's commitment to the 
EFPIA/PhRMA "Principles for responsible clinical trial data sharing". This pertains to scope, time point, and process of data access. As such, Bayer commits to sharing upon request from qualified scientific and medical researchers patient-level clinical trial data, study-level clinical trial data, and protocols from clinical trials in patients for medicines and indications approved in the US and European Union (EU) as necessary for conducting legitimate research. This applies to data on new medicines and indications that have been approved by the EU and US regulatory agencies on or after January 1, 2014.

Interested researchers can use www.clinicalstudydatarequest.com to request access to available datasets and supporting documents from clinical studies to conduct further research that can help advance medical science or improve patient care. Information on the Bayer criteria for listing studies and other relevant information is provided in the "Study sponsors" section of the portal. Data access will be granted to available datasets, protocols, and clinical study reports after approval by an independent scientific review panel. Bayer is not involved in the decisions made by the independent review panel. Bayer will take all necessary measures to ensure that patient privacy is safeguarded.

\section{Abbreviations}

BMI, body mass index; COC, combined oral contraceptive; DCE, discrete choice experiment; IUS, intrauterine system; LEP, low-dose estrogen progestin; MSS, mean sum of squares; NSAID, nonsteroidal anti-inflammatory drug; OR, odds ratio; OTC, over-the-counter; RI, relative importance; SAS, Statistical Analysis System; SD, standard deviation; VTE, venous thromboembolism.

\section{Acknowledgments}

The authors acknowledge Eugenia Peck, PhD, and Kristen K Concialdi, BS, who contributed to study and survey design, data collection, and reporting, Shawna Calhoun, MPH, who contributed to writing, and Martine $\mathrm{C}$ Maculaitis, $\mathrm{PhD}$, who contributed to literature review and writing, on behalf of Kantar Health, with funding from Bayer Yakuhin, Ltd. The current study was funded by Bayer Yakuhin, Ltd.

\section{Author contributions}

Tasuku Harada, Tetsushi Komori, and Sayako Akiyama contributed to study and survey design, reporting, and manuscript writing. Amir Goren and Enrique Basurto contributed to study and survey design, analysis, reporting, and manuscript writing. All authors contributed to interpretation of data, critical revision of the paper and final approval of the version to be published, and all authors agree to be accountable for all aspects of the work.

\section{Disclosure}

Sayako Akiyama and Tetsushi Komori are employees of Bayer Yakuhin, Ltd. Tasuku Harada is a paid medical advisor to Bayer Yakuhin, Ltd. for the study and outside of the study. He has received funding from Fuji Pharma Co., Ltd., Mochida Pharmaceutical Co., Ltd., Nippon Shinyaku Co., Ltd., and Nobelpharma Co., Ltd., outside of the study. Amir Goren and Enrique Basurto were employees of Kantar Health at the time of the study and conducted the study with funding from Bayer Yakuhin, Ltd. The authors report no other conflicts of interest in this work.

\section{References}

1. Lentz G, Lobo R, Gershenson D, et al. Comprehensive Gynecology. Philadelphia, PA: Mosby Elsevier; 2012.

2. Impey L, Child T. Obstetrics and Gynaecology. Chicester: WileyBlackwell; 2012.

3. Latthe P, Latthe M, Say L, Gülmezoglu M, Khan KS. WHO systematic review of prevalence of chronic pelvic pain: a neglected reproductive health morbidity. BMC Public Health. 2006;6:177.

4. Ohde S, Tokuda Y, Takahashi O, Yanai H, Hinohara S, Fukui T. Dysmenorrhea among Japanese women. Int J Gynaecol Obstet. 2008; 100(1):13-17.

5. Tanaka E, Momoeda M, Osuga Y, et al. Burden of menstrual symptoms in Japanese women - an analysis of medical care-seeking behavior from a survey-based study. Int $J$ Womens Health. 2013;6:11-23.

6. Tanaka E, Momoeda M, Osuga Y, et al. Burden of menstrual symptoms in Japanese women: results from a survey-based study. J Med Econ. 2013;16(11):1255-1266.

7. Nohara M, Momoeda M, Kubota T, Nakabayashi M. Menstrual cycle and menstrual pain problems and related risk factors among Japanese female workers. Ind Health. 2011;49(2):228-234.

8. Barnard K, Frayne SM, Skinner KM, Sullivan LM. Health status among women with menstrual symptoms. $J$ Womens Health (Larchmt). 2003;12(9):911-919.

9. Rodrigues AC, Gala S, Neves Â, et al. [Dysmenorrhea in adolescents and young adults: prevalence, related factors and limitations in daily living]. Acta Med Port. 2011;24 Suppl 2:383-388; quiz 389-392. Portuguese [with English abstract].

10. Sharma A, Taneja DK, Sharma P, Saha R. Problems related to menstruation and their effect on daily routine of students of a medical college in Delhi, India. Asia Pac J Public Health. 2008;20(3):234-241.

11. Al-Jefout M, Seham AF, Jameel H, et al. Dysmenorrhea: prevalence and impact on quality of life among young adult Jordanian females. J Pediatr Adolesc Gynecol. 2015;28(3):173-185.

12. Ayan M, Sogut E, Tas U, et al. Pain levels associated with renal colic and primary dysmenorrhea: a prospective controlled study with objective and subjective outcomes. Arch Gynecol Obstet. 2012;286(2):403-409.

13. Rencz F, Gulácsi L, Varga AN, Sziklai OR, Péntek M, Brodszky V. Time trade-off utility values in mild and severe primary dysmenorrhea. Value Health. 2015;18(7):A738-A739.

14. Iacovides S, Avidon I, Baker FC. What we know about primary dysmenorrhea today: a critical review. Hum Reprod Update. 2015;21(6): $762-778$.

15. Akiyama S, Tanaka E, Cristeau O, Onishi Y, Osuga Y. Evaluation of the treatment patterns and economic burden of dysmenorrhea in Japanese women, using a claims database. Clinicoecon Outcomes Res. 2017;9:295-306. 
16. Taketani Y. [Investigating the prevention, diagnosis and treatment of conditions including endometriosis from the perspective of reproductive health (health related to sex and reproduction)]. Ministry of Health, Labour and Welfare research report for the 2000 fiscal year. Tokyo: Ministry of Health, Labour and Welfare, National Institute of Public Health; 2001:503-550. Japanese.

17. Marjoribanks J, Proctor M, Farquhar C, Derks RS. Nonsteroidal antiinflammatory drugs for dysmenorrhoea. Cochrane Database Syst Rev. 2010;(1):CD001751.

18. French L. Dysmenorrhea. Am Fam Physician. 2005;71(2):285-291.

19. Morrow C, Naumburg EH. Dysmenorrhea. Prim Care. 2009;36(1): 19-32, vii.

20. Japan Society of Obstetrics and Gynecology (JSOG) and Japan Association of Obstetricians and Gynecologists (JAOG). Guidelines for office gynecology in Japan, 2017 edition. Tokyo, Japan: JSOG; 2017. Japanese.

21. Lindh I, Milsom I. The influence of intrauterine contraception on the prevalence and severity of dysmenorrhea: a longitudinal population study. Hum Reprod. 2013;28(7):1953-1960.

22. Manzoli L, De Vito C, Marzuillo C, Boccia A, Villari P. Oral contraceptives and venous thromboembolism: a systematic review and meta-analysis. Drug Saf. 2012;35(3):191-205.

23. Beatty MN, Blumenthal PD. The levonorgestrel-releasing intrauterine system: safety, efficacy, and patient acceptability. Ther Clin Risk Manag. 2009;5(3):561-574.

24. Berkley KJ. Primary dysmenorrhea: an urgent mandate. Pain. 2013; 21:1-8.

25. Kamel DM, Tantawy SA, Abdelsamea GA. Experience of dysmenorrhea among a group of physical therapy students from Cairo University: an exploratory study. J Pain Res. 2017;10:1079-1085.
26. Magai C, Consedine N, Neugut AI, Hershman DL. Common psychosocial factors underlying breast cancer screening and breast cancer treatment adherence: a conceptual review and synthesis. $J$ Womens Health (Larchmt). 2007;16(1):11-23.

27. Bridges JF, Hauber AB, Marshall D, et al. Conjoint analysis applications in health - a checklist: a report of the ISPOR Good Research Practices for Conjoint Analysis Task Force. Value Health. 2011;14(4):403-413.

28. Kuhfeld WF. Marketing research methods in SAS: experimental design, choice, conjoint, and graphical techniques. SAS 9.2 edition. Technical report MR-2010. Cary, NC: SAS Institute, Inc.; 2010.

29. Dar FH, Meakin JR, Aspden RM. Statistical methods in finite element analysis. J Biomech. 2002;35(9):1155-1161.

30. Benson LS, Micks EA. Why stop now? Extended and continuous regimens of combined hormonal contraceptive methods. Obstet Gynecol Clin North Am. 2015;42(4):669-681.

31. Stegeman BH, de Bastos M, Rosendaal FR, et al. Different combined oral contraceptives and the risk of venous thrombosis: systematic review and network meta-analysis. BMJ. 2013;347:f5298.

32. Lindhiem O, Bennett CB, Trentacosta CJ, McLear C. Client preferences affect treatment satisfaction, completion, and clinical outcome: a meta-analysis. Clin Psychol Rev. 2014;34(6):506-517.

33. Briggs P, Serrani M, Vogtlander K, Parke S. Continuation rates, bleeding profile acceptability, and satisfaction of women using an oral contraceptive pill containing estradiol valerate and dienogest vs a progestogenonly pill after switching from an ethinylestradiol-containing pill in a real-life setting: results from the CONTENT study. Int J Womens Health. 2016;8:477-487.
Patient Preference and Adherence

\section{Publish your work in this journal}

Patient Preference and Adherence is an international, peer-reviewed, open access journal that focuses on the growing importance of patient preference and adherence throughout the therapeutic continuum. Patient satisfaction, acceptability, quality of life, compliance, persistence and their role in developing new therapeutic modalities and compounds to optimize

\section{Dovepress}

clinical outcomes for existing disease states are major areas of interest for the journal. This journal has been accepted for indexing on PubMed Central. The manuscript management system is completely online and includes a very quick and fair peer-review system, which is all easy to use. Visit http://www. dovepress.com/testimonials.php to read real quotes from published authors. 